\title{
MECHANICAL PROTECTION FOR THE VIOLENT INSANE.*
}

Challenge of Dr. J. C. Bucknill.-What is Mechanical Restraint?-Philosophy of Restraint.-Why Mechanical is preferable to Manual Control.Mild Treatment long the Practice in America.-Movement for Exclusive Manual Restraint in England.-Evils of Laxity of ('ontrol.-Illustrative Cases.-Differences of Opinion among the English.-The Status of Restraint in the United States. - Experience of Dr. Walker in England.Some Questions for Dr. Bucknill.-Adherence to our Convictions, the Path of Duty.

EUGENE GRISSOM, M. D., LL. D. Superintendent of the Insane Asylum of North Carolina.

In a recent publication entitled "Notes on Asylums for the Insane in America," by the distinguished John Charles Bucknill, M. D., F. R. S., appears the following declaration : $\uparrow$

"The pages of The Larcet are not likely to influence the politicians of New York, who think their insane sufficiently well cared for in the asylums I have described; neither will they have much weight with the gentlemen at Philadelphia, who are in the habit of placing three violent lunatics to sleep (?) in the same cell, prudently enough protecting them in some degree by strait-waistcoats. But it is to be hoped that a fair and frank challenge to the medical superintendents of the State asylums and the hospitals for the insane will be accepted in the friendly spirit in which it is given, and that they will not refuse to show reasons why they adhere to a mode of treatment which, in this country, is condemned by the almost unanimous voice of the profession and of the public."

* Read before the Association of Superintendents of American Institutions for the Insane, at the meeting held at St. Louis, Mo., May, 1877.

† Reprinted in Journal of Insanity, October, 1876, p. 147. 
We have here a distinct challenge, declared by its distinguished author to be "fair and frank," as to the propriety of certain means of treatment employed by the American superintendents in the care of the insane.

It is no unknown personage who has thus arraigned this Association before the bar of medical opinion of all Christendom. It is the learned author and experienced superintendent of the insane who says :*

"I have been able to come to no other conclusion than that the great stumbling block of the American superintendents is their most unfortunate and unhappy re. sistance to the abolition of mechanicil restraint."

It is the celebrated Commissioner in Lunacy of Great Britain who declares, $\uparrow$

"Unless I am much mistaken the superintendents of asylums in America have a heavy task before them, which will indeed require a determined effort before they can say that they possess the confidence of the public in the same degree to which, of late years, it has been extended in England, to the management of our county asylums and hospitals for the insane."

$I_{t} t$ is the first honorary member of the American Association of Medical Superintendents of Asylums for the Insane, and late their honored guest, who publishes to the world such statements, and challenges their denial:

"They are men, as I most willingly testify, animated by the highest motives of humanity, but ignorant and mistaken in their application of means to the futherance of that great end to which we all press forward, namely, to the care and cure of the insane, with the least amount of suffering."

If any apology is needed for an affirmation of our position on this subject, it may be found in the claims 
of the gentleman from whom I have quoted, as we learn by recent letters, that his trenchant appeals have produced a profound effect upon American alienists. His hopes and predictions are that, "they (we) will sink five fathoms deep their (our) bonds of hemp and iron." We are informed by him that an eminent phy. sician* expresses regret that Dr. Bucknill did not make a complete tour of American asylums, in order to inform those superintendents thus "ignorant and mistaken." Expression of satisfaction also appear that certain alienists are changing their practice, are learning these new methods, and so will "be able to reinstate themselves in the front ranks of practical philanthropy."

If these things are true, if indeed this Association is ignorant, mistaken, prejudiced, every consideration for suffering humanity demands that we recognize our faults, and with a courageous hand tear down any traditional bars or obstacles that stand in the way of our duty, toward those whom God and the laws of our country have placed in our hands. But should we find these charges of incompetency in office, and the dissatisfaction of the people consequent thereupon to be untrue, courtesy should not perhaps bar the way to a "fair and frank" reply. If these charges were made by an anonymous writer, we should not scruple to say that they were presumptuous, unscientific, tinctured with selfconceit, and if the gravity of the topic did not prevent, not far from absurd.

It is to be regretted, in one point of view, that the term restraint was ever applied to the various means employed for the protection, safety and welfare of the insane, and others immediately about them. The insane man, with feelings or inclinations disordered by disease; with excess of irritability; with loss of will-power ade- 
quately to control his appetite, tossed hither and thither by his emotions and passions, the offspring of a diseased brain; sometimes without memory, always without intelligent judgment; perhaps rent and torn by epileptic shocks, or driven to suicide or homicide, needs above all things, protection from himself. He needs at the hands of his fellow man, rest and comfort, aid and protection against his changed self.

A proposition so self-evident need not detain us. It is undisputed. Such a thing as absolute non-restraint of the insane is utterly unknown, except perhaps among the Malays, where mutual slaughter finally effects restraint. We will not do the injustice to the advocates of what, by an absurd misnomer, has been termed "nonrestraint" to confound their position, even with the extreme views of Fife and Kinross, with their unlocked doors, and benevolent patients who sustain the institution, from a sense of duty, except indeed when they prefer to retire to the padded room for meditation, or occasionally hreak a neck in illustrating the beauty and propriety of unguarded windows, or sit with locked arms between two attendants.

Not even Dr. Bucknill, perhaps, will accept the chimera of the worthy Dr. Batty Tuke, and we shall waste no time in discussing manifest impossibilities.

The truth is, that the normal and the abnormal are present, together, in the insane. We have before us good and evil, bound up in the same body-whatever restrains the evil, protects the good. Why not mechanical protection of the insane, rather than mechanical restraint? A word is sometimes a power, to the modern mind, even reaching to the greatest individualism of character and government. Restraint savors of. tyranny, and carries with it the implication of a sacrifice of the better liberty, to the meaner arbitrary rule. 
The practice of alienists, in America has been put in a false position. What was known as "restraint" in former ages, was in the nuain really punishment. The insane were made to suffer as for crime, and were not treated as if diseased. This is the very pivotal point of the discuss:on. We deny that restraint, as known to asylums in America, is used as punishment, in any sense. With equal propriety, wi:en Dr. Sayre wraps a victim of Pott's disease in a plaster jacket, or fits a leg in complicated, hut ingenious apparatus, to prevent injury by motion or while in sleep, to cure deformity, may he be accused of cruel and inhuman restraint. The patient under a capital surgical operation is held, to prevent him from injuring himself amid uncontrollable pain, and sometimes he is bound to the operating table. Yet does not the very hand of humanity hold him most securely? Necessary restraint is as truly a blessing to him who would otherwise dash out his brains, as the crutch is to the shrunken limb, or the cane to the wearied frame. If, as we ha'e seen, the sane must necessarily control, or if you please, restrain the insane, as the very erection of hospitals provides for, the true question for the medical mind is, how shall it be best accomplished, when required? We have to choose between the hypnotic power of drugs, affording the "chemical restraint of the brain cell," or the manual restraint of the strong arms of attendants, or that of solitary imprisonment in seclusion, as advocated and employed by our English brethren, or the mechanical restraint of a strap, restraining the patient to a chair, a camisole, or a muff, or the covered bed. There are patients who mal. treat others; who would cut, or bruise, or otherwise injure themselves; who would tear off their clothing; who would wear themselves to death by maniacal exhaustion, with ceaseless muscular struggles; who would 
devour abominations; outrage the decencies and sensibilities remaining to their fellow patients; make day and night a perpetual torment to themselves and all within their reach, retarding their own and the cure of others, and hopelessly prolonging their sufferings. Which of the above means of restraint shall we employ.

The true answer we conceive is, any and all means that we may find by experience, to be most serviceable, should be adopted.

There may be cases in which the administration of drugs would be followed by harmful consequences, or the effect would be too transient to serve the required purpose. There may be cases in which seclusion would be pr sductive of evil and ruinous habits, or excite the most fearful terror. We are driven, then, to choose between mechanical and manual restraint. And here is the question that is really at issue between the American practice, and that of some of our English brethren.

Shall we confine ourselves, in case of necessity, to one of these means of protection for the lunatic, or avail ourselves of both, as circumstances may dictate?

It is as though in another sphere of medical art it were asked, must iron be thrown away, because we have quinine, or shall the tourniquet be forgotten, because Esmarch's bandage may be obtained? Pray what moral disability accompanies the use of mechanical restraint, to make it so black in the eyes of our British brethren, which is not to be found in the use of manual restraint? When they say, we deal with patients who need no restraints, we reply that manual holding is quite as much restraint as mechanical.

Many reasons may be suggested which exhibit the advantages of linen or leather muffs or bands,"or leather wristlets, or the covered bed, over the threatening glances, or the hard grasp of four or five attendants, 
holding the patient through the struggle of hours, perhaps prolonged to days. Mechanical restraint is far better, we believe, in many cases:

1. Because of the absence of the personal antagonism between the attendant and the patient, sure to arouse evil passions stirring to excitement, and followed by proportionate depression.

2. Because of the certainty and uniformity of its action, unaffected by momentary strength or weakness, by sudden access of feeling, or the impatient weariness of fatigue.

3. Becallse it does not excite the passions of the patient, by the mere sight of disturbance in the overwrought and worn-out attendant.

4. Because when recognized as irresistible, it may be said to establish an environment which the patient accepts, as there is no hope of suddenly overcoming it.

5. Because it is far better, for female patients. especially the epileptic and hysterical, than the sight of long continued struggles with attendants. On the other hand, if manual restraint is only used out of sight, then seclusion is added, with its evils.

6. Because it is better than the physical exhaustion of the patient, from contest with attendants, which may be long continued and serious, even fatal not intrequently, when the irritability of the patient is great, while his vitality is really low.

7. Becuuse it may be applied uniformly at night when necessary, to the suicidal, who could not otherVol. $\mathrm{XXXIV.-No} \mathrm{I-C.}$ 
wise be safely cared for, unless at enormous expense, and with the disadvantage of the attendants keeping the patient awake by their presence.

8. Because, in a mild form, it may be applied to the homicidal during the day, and still allow him out-door air and exercise, with safety.

9. Because it may save the cases of violent acute mania of whose prognosis we are most hopeful, if no traumatic troub'e happens to break down the general vigor of the system.

Really when one considers the history of the provision for the insane, during the past hundred years, both in Europe and in our own country, and reflects that our opponents claim is only this, that they from being the representatives of every form of mechanical restraint, have only substituted that of human hands and retained seclusion, there would seem but little to discuss. One feels like saying with Isaac of old, "The voice is the voice of Jacob, but the hands are the hands of Esau."

All badinage aside, is it not a sorry sight to behold a philosopher who has discovered that "the great stumbling-block of the American Superintendents is their most unfortunate and unhappy resistance to the abolition of mechanical restraint" as a consequence of which they, (we) have not the confidence of the public.

Let us examine briefly the history of this subject. No superintendent of an asylum will do his duty, who is content with anything less than the most humane, the most liberal, the most enlightened, the most noble and elevated treatment of the poor sufferers whom he has in charge. The true physician of the insane acknowledges with a famous Englishman, that 
A man is what he knows; of created baings the most excellent are those who steadily employ their gift of reason for the glory of the Creator, and the relief of man's estate.

If we are wrong, let us throw our idols to the moles and bats, but if it be not so, why these half apologies in some of the annual reports of our asylums; these references to the performance of our duty in one mode of medical treatment, with bated breath, and hopes for its speedy extinction, as a duty? There is no running away from this question, nor need we seem to avoid it. History confirms the justice of our course-experience affirms its propriety. It is time to say to that sort of sentimentalism which would kill a patient to save a theory, that it shall go no farther. We take the responsibility to do what is right, let it please the popular ear or not.

It is not needful that I should say to you that Americans did not wait to learn humanity from Conolly and his noble compeers. You have ha! a happy description of the treatment, wise and humane, at the McLean Asylum, before a new day dawned upon such institutions in England, as the unhappy Lincoln Asylum, with the cruel restraint of the patients and riotous life of the keepers.

The records, and the annual reports of our best institutions show, from 1820 to the present time, there has been a general voice of the profession in favor of the most humane and tender treatment, and yet keeping firm control of all the means that might prove advantageous. Length of years has only justified the calm conservatism of the alienists of the Union. And to the present day, the careful and limited use of mechanical means of protection for the violent insane, is a part of the treatment of nearly all American asylums.

The need of mechanical restraint, its due use, as distinguished from abust, and the various cases in which 
it proves a valuable, if not essential adjunct, to the best treatment, have been exhaustively discussed and explained, and notably so in the interesting report of remarks upon the paper of Dr. Rinney, submitted at the Nashville meeting.

It is unnecessary to quote the repeated expressions of my brethren around me, on record in the Joursal, or to recur to the long line of authorities, fortified by the experience of a lifetime among the insane.

But in Great Britain, usage has recently been different. Refusing to distinguish between mechanical restraint for punishment, and that which was used for protection, many of the profession accepted the dogmas of philanthropic doctrinaires, and among them, that the insane inan must not be restrained. It was noble and praiseworthy in its theory, but impracticable, and necessarily became a pretense, secretly supported by seclusion rooms, until by degrees, seclusion was openly advocated to take the place of mechanical restraint.

There were some physicians, even in the midst of the philanthropic whirlwind, who thought it better to risk a little chafing of the skin in a camisole, than to break a half dozen ribs by the knee of an attendant, and who looked with thoughtful gaze upon the long and lament. able list of casualties in the asylum reports.

Now and then, through a series of years may be heard the cry of an anxious heart, oppressed by a public opinion built upon ignorance of the needs of disease, and led by the arrogance of self-satisfied Commissioners who required of physicians, that they should make bricks without straw.

From many reports that might be cited, I quote Dr. J. Grieve in the 19th Annual Report of the Crichton Royal Institution, for 18j8.*

*19th An. Rept. Crichton Royal Inst. 1858, p. 12 Dr. J. Grieve. 
Mechanical restraint has been employed in only one instance during the year-in the case of a female with epileptic mania. The patient had just been admitted, and was suffering from an attack of that blind reckless fury, not uncommonly assuciated with epilepsy. On visiting the patient, she was found placed in a padded arm-chair, and held there by the united force of three attendants, the reason assigned being that she had severely bitten her arm. As the wound was deep and extensive, and every indication was given that the act would be repeated, the application of the ordinary muff was decided upon.

The wound in the arm was followed by violent asthenic inflammation, terminating in extensive destruction of tissue, the establishment of sinuses \&c.- - had many instead of one of these wounds been inflicted, we have no doubt life would have been seriously compromised if not forfeited."

He then describes at length the padded bed, covered with a girth netting which is used for an intermittent suicidal and homicidal patient.

Those who take special views, "says he," (Dr. Grieve,) will object to the so-called degradation of the patient, and insist upon more attendants. The slightest interference is the signal for a furious attack. Contemplating the struggles that might ensue, even in a single night, we can not but prefer the compulsory quiet to the licensed excitement. We are not sure, however, that these and like appliances may not be pleaded for, on higher grounds. A case illustrative comes to mind.*

Some three years ago, a patient usually quiet and industrious, had paroxysmal attacks with suicidal impulse. After long pleading from her for the "strait jacket," which had been used at home, it was conceded. She was thus effectually prevented from inflicting the injuries upon herself, which she was impelled, yet dreaded to do. Self-confidence and a sense of safety were thus secured. which could not be obtained from the presence of any number of attendants. The happy results were again and again witnessed, and they left no doubt of their origin. Is it to be wondered at? If it be true that the sight of a bridge or a river will raise within the breast of the suicide the dormant impulse; and if it be a consequent duty on the part of the physician, to conceal, if possible, these objects from his view, surely the same law demands, and the 
same duty urges the removal of, it may be, more common, yet not less powerful incentives, providing it can be done without inflicting a greater injury. Is there not reason for asking the question, whether, under the dread of "mechanical restraints," we have not been frightened from the legitimate use of mechanical appliances; whether we are not losing sight of important principles, under the talismanic influence of mere phrases.

Witness the following from the Thirty-seventh Report of the Royal Asylum at Perth, for 1864:*

Notwithstanding every care taken to prevent their occurrence, many unforeseen assaults have been committed during the yearnot unfrequently, on the attendants placed in special charge of dangerous patients. We may add, by the way, that such accidents would scarcely have occurred under the old regime of manual restraint, which, with all its faults, had its advantages, and which undoubtedly saved, in more than one form, many lives that are now sacrificed to the popular creed, " non-restraint," absurdly so-called. The fact can not be doubted that reaction against the errors and absurdities of the "absolute non-restraint" system is setting in strongly. Asylum physicians find that mechanical restraint is the most humane mode of treating certain exceptional phases of insanity - the only mode, apparently, of avoiding certain catastrophes, now of common occurrence; and the $y$ are gradually readopting the mildest forms thereof compatible with the safety or security of their patients. But with the present strong public feeling in favor of unqualified non-restraint-the total abolition or absence of restraint in or under all its forms or names-a feeling which is not founded on experience, but is merely the fruit of the pseudo-philanthropic tendencies of the age-it is exceptional to find men with the moral courage necessary to the confession that their experience, if not belief, is antagonistic to the favored creed or delusion of the time.

Dr. Lindsay + also mentions the case of a patient transferred to his care, who had been under the hands of more than ten unskilled attendants, while in a state of acute manı. The numerous bruises showed, said he, the nature of the home treatment ; the probability being, that had the camisole been applied, the injuries would not have been inflicted. The death of the patient was accelerated, if not directly caused, by violence in handling.

* 37th Annual Report, Murray Royal Asylum, Perth, 1864, p. 12. Dr. W. Lauder Lindsay.

† Murray Royal Asylum, Perth, 18i4. Dr. W. L. Lindsay. 
Here and there, although there is a proclamation of non-restraint in the decorous columns of the annual reports of many Euglish asylums, it is not uncommon, in the published reckoning of expenses, to find items of at least doubtful meaning, as so many pounds and shillings for "strong shirts" or "canvas," or, as in the Report of the Friends' Retreat at York, for 1876, an account of the painting of "seclusion room and passages," or as in the Thirteenth Annual Report of the Worcester Asylum (p. 51,) the following significant line, "stuffiing pads for strong room-5

In more recent years there have not been wanting men of courage who have set themselves boldly against the pretense of non-restraint, on the high ground of duty. In the Forty-fourth Report of the Belfast Hospital for the Insane for 1873, Dr. Robert Stewart, Governor, (appointed by the Lord Lieutenant of Ireland,) will be found the following:*

It has been the exception to the rule during the past year, the having recourse to mechanical restraint, the disuse of which has been the regular practice here since the opening of the Institution, in $1829, \uparrow$ but in stating this it is not to be understood that cases do not occur in which it would be nothing short of both an act of cruelty, as well as a dereliction of duty, not to use the restraint of a camisole, or such like mild form of coercive means, for the preventing of danger to both patient and attendant, and no morbid fear of consequences should prevent medical superintendents from this discharge of a bounden duty towards their patients, when the occasion demands it of them.

Honor to the men who are not afraid to speak the whole truth, even as against a popular sentiment, begun by a mistaken idea of philanthropy, and fostered by sensational novelists of the stamp of $\mathrm{C}^{\prime}$ arles Reade.

* 44th An. Rept. Belfast Hosp. for Insane, 1873, Dr. obt. Stewart, Gov . Pub. 1874.

pp. 28-30. 
What necessities arise for the use of restraint may be gathered from an extract from the report last alluded to :

Here it may be appropriately stated, that during the past year the resident physician escaped almost by a miracle, a sudden and violent termination of his life, having been attacked on two separate occasions by two male homicidal inmates-in the first instance by an attempt at strangulation, and in the second by a severe stab in the face, close to the eye, with a sharpened knitting needle, which had it entered it, would most likely have been fatal. On two occasions afterward the same patient who stabbed the resident physician, similarly injured two of the male attendants, one on the face also, the eye having been wounded.

It is only a few months since one of the Commissioners of Lunacy, in England, met with an untimely death. He was officially visiting a hospital, and passing through a ward (where it was evident that the risk was taken in order to display non-seclusion and non-restraint,) when by the side of the medical superintendent, he was struck in the temple with a sharpened piece of iron by one of the chronic patients, and died a day or two after.

In the Twenty-first annual Report (1874,) of the Worcester (England,) Asylum, may be found the following : *

During the past year a suicidal wave has been perceptible in the persons under our care. Several during the day made determined efforts upon their lives, while in the presence of their guardians. These were all detected, and resulted fortunately, in no permanent injury. Two, however, of this class, were unfortunately allowed by their attendants to separate themselves from the ever-present supervision essential for their safety, and in consequence were enabled to effect their purpose.

He states further that there had been apparent im. provement in both cases, when the culpable violation of regulations on the part of the attendants, viz.: not to permit such persons to be out of observation, resulted in disaster. He says farther:

In connection with this suicidal type of mental disease, another complication remains to be mentioned. Many patients, both of

* Dr. James Sherlock, p. 96. 
1877.] Mechanical Protection for the Insane.

the male and female sex, for months persistently employed themselves in causing solutions of continuity of the soft textures. This propensity existed not only during the night, but was carried on during the day in the most open manner, in spite of all remonstrances, entreaties and arrangements. Restraint was not employed to circumvent this perversion, but relays of persons were told off to guard against the continuance of the practice, and with only partial success.* * * Your superintendent has no reason to regret the course pursued in these cases; some of them have left the Asylum in an improved state of bodily and mental healtb, others remain here suffering from chronic insanity with symptoms indicating the existence of brain disease, the impulse in question has been abated, although not entirely suspended.

The logic which deduces such a conclusion from such premises is unanswerable.

It is to be observed of the same Institution under charge of the same gentleman, that in 1875 , the twenty-third Annual Report records the following: $†$

Seclusion has been resorted to in the cases of thirty-one men and twenty-seven women; with the former on one hundred and sixtynine and the latter on one hundred and nine occasions.

The question has been repeatedly pressed by the critics of American practice, to name the classes of patients in which we find the use of restraint serviceable. Without regard to the captious manner of the question, many of my brethren have answered, and the literature of the subject is rich in cases which it would be superfluous to relate. It may not be improper, how. ever, to give some instances from the Case Books of the North Carolina Asylum for the Insane, of which I have charge, which will illustrate our clinical practice in regard to the several moles of protective restraint.

I. H. Epileptic Mania. Has paroxysms of viclent excitement during which he imagines that himself and

* Worcester 21st An. Rept. 1873, p. 97.:

† Worcester, Eng. 23d An. Rept. 1875, Dr. Sherlock. 
Journal of Insanity. [July,

others are engaged in building, or tearing down log houses, or other work requiring great force. $\mathrm{He}$ is proud of his strength. and to use his expression, "likes to fout for the fun of the thing." $\mathrm{He}$ is restrained to prevent violence to himself and others.

D. B. Chronic Mania. Was an open masturbator. At times excited and noisy at night, and practiced the habit in disgusting excess when he had the free use of his hands. It was directed that they be restrained. In the opinion of the writer, restraint has been of much serrice in his treatment.

V. V. Chronic Mania. A listrustful, suspicious man, who will quietly fix his eyes on some particular person, and without notice of his intention, seize his rictim by the throat in the most determined manner.

W. P. B. Chronic Mania. Has paroxysms during which he will swallow anything practicable. On one occasion swallowed a piece of tin one inch square.

W. G. A. Melancholia. Refuses any request whatever. With much persuasion and some force, he eats enough to sustain life. Will not permit an action of the bowels if he can prevent it. To prevent urination, he places a ligature round the penis. To correct this, he is restrained at night, and watched in the day.

W. H. H. Melancholia. Strong suicidal tendencies. Has attempted to kill himself on several occasions. From his deportment, and the character of his delusions, he would probably succeed, if not prevented by restraint at night, and being watched during the day.

W. G. Chronic Mania. An open, unblushing mas. turbator, violent to self and others. Consider re. straint of hands and out-door freedom better treatment than seclusion.

J. P. Chronic Mania. Persistently destructive to the clothing of himself and others, and to anything he 
can depredate upon, and disgustingly filthy in his personal habits. His hands restrained at times prevent all these.

Dr. I. L. R. Homiciclal Mania. Has on several occasions made most violent attacks on others. After so doing, he assigns as a reason, that his victim was plotting to injure him. He is restrained in the day, and relieved at night.

M. A. Chronic Mania. Restraine:l to prevent violence to others, and to self, exposure of person, and the destruction of clothing and furniture generally.

V. I. Chronic Mania. Restrained to prevent vio lence to others, and injury to self by abusing her person in various ways, as by slapping herself, beating her head, and plucking out her eyeballs. She unfortunately destroyed one eye, before she was adequately restrained.

M. W. Chronic Mania. Restrained to prevent masturbation and violence.

C. L. Mania. Subject to paroxysus of excitement, during which she will use any moveable thing, as a weapon on selected victims, which she has secreted while in a state of quiet.

F. W. Mania. When admitted, was excited and violent, and a persistent masturbator. He was treated with chloral, morphine and other remedies at night, but no bencfit or improvement was shown until his hands were restrained. Is at home on probation, with fair prospects of recovery. Without restraint, he would probably now be in the Institution, in a worse condition than when received. It is proper to remark that by a provision of the State law, quiet and supposed harmless patients are from time to time removed to make room for the violent and dangerous cases that disturb the public peace.

We have one covered bedstead, and one strong room, but no padded rooms. The forms of restraint are of 
the mildest character, consistent with effective value, but they are unhesitatingly prescribed and used as medical treatment.

After all, it is upon results that we must stand or fall. We will not rashly affirm that it is in consequence of continual struggles with attendants, and the annount of personal license, by night and day, allowed to the violent insane, that the long lists of casualties are to be found in the English reports; casualties whose details are so terribly suggestive of mortal combats or stealthy maniacal assassination.

We would not lightly use the tu quoque argument in a discussion upon a great fundamental principle of treatment of the insane. It is not the petty triumph of a bitter paragraph that we seek. But the facts are so momentous, and their bearing so decisive upon this question, that we are impelled to the ungracious task of pointing out the fatal deficiency in manual restraint, called "non-restraint," by the vision of the victims yearly sacrificed on the altar of an ideal dream. May their pallid lips speak from the grave in emphasis solemn and conclusive!

In a recent number of the Journal of Psychological Medicine and Mental Pathology, England, may be found an article entitled, "Quis C'ustodiet Custodes?" which recounts the homicides and injuries inflicted by persons of doubtful sanity within and without asylums, gathered from a limited number of periodicals, during the space of five months.

The author, who was a superintendent of an asylum for twenty-five years, says that he lives now a life of retirement, but still lives to learn. In a vein of exquisite irony he writes that the newspapers have taught him that his "opinions as to the immutability or indelibility of forms of derangement and degeneration were 
altogether erroneous and untenable; that the type of mental disease had changed; that the mania furibunda described by former psychologists, and sculptured by Cibber was antiquated and forgotten; that there have been no pyromaniacs since Jonathan Martin, no insane parricides since Dodds, no insane regicides since Oxford; no homicides since the martyrdom of Myer and Lutwidge; that walls have been leveled, bolts and bars melted into ploughshares, and that seclusion in an asy. lum was now converted into sport in Arcadia. Now I am not old or soured enough to snarl sceptically at all this, to doubt that the reign of humanity is twice blessed, to set any limits to the powers of nature or of moral medicine. But I am sadly perplexed when there comes, through precisely the same channels, the hope-inspiring and the hlood stained streams almost mingling together, the following facts:

1. That within a few months an attendant was killed by a lunatic in Leicester Asylum; 2. That one lunatic killed another in Durham County Asylum; 3. That a lunatic was killed in Greenock Poor House Asylum, and that an attendant was accused of killing him; and 4, That a lunatic was reported to have had his ribs fractured, \&c., by an attendant in Northwoods Asylum, both being intoxicated at the time, the assailant being subsequently tried and sentenced in the penalty of a fine of $£ 15$, and two months imprisonment. Now my olject is not to attribute the slightest degree of culpability, malpractice, or misadventure to any one connected with the above deplorable accidents, but simply to show that there must have been struggle, violence, fury, ferocity previous to the death blow. Nor, in adverting to one hundred and sixty instances of accidents, including several suicides, stated to have occured within the safe and sacred precincts of asylums in Scot- 
land in 1874-1875, in the annual report of the commissioners-which is the only record of such important data that we know of-would we breathe or harbor the suspicion that there was either negligence, or carelessness, or inadventure, or the absence of such precaution as might have prevented fiactures and blows and burns, as our only wish is to direct attention to the sad evidence afforded that "the Millenium has not yet arrived in Bedlam."

Brief statements are then given of forty-nine cases, including suicides, homicides, deaths from neglect, violent homicidal attacks, and injuries upon self and others.

In an article entitlel "Lunacy in the Uniter States," published in the British Melico-Chirugical Review, for July, 1876, appears the following:

We lately conversed with a superintenclent, who led, perhaps awed, by the example of Conolly, never resorted to restraint, whose career has nearly reached that crisis when our professional as well as our personal errors come to be reviewed and repented of, and whose concluding sentence was, "Three things I bitterly regret1st, that I trusted too little to stimulants; 2 nd, too little to opium; $3 \mathrm{~d}$, too little to restraint."

In the London Lincet, of March 18th, 1876, and subsequent numbers, Dr. Bucknill writes as follows:*

I regret that it did not occur to me to ask in this or in any other American asylum, to be permitted to inspect the register of injuries and accidents; but if such a record be kept, I think it more than probable that a faithful com? ?arison of it with that which the law imposes on our own institutions would clearly prove that non restraint does not encourage, nor restraint diminish or prevent the occurrence of injuries from violence.

'This has so much of the humor of Charles Lamb, with his fashion of linking quaint unlikenesses, that one instinctively reads again to be sure that the

*Dr. Bucknill Art. in Lancet, March 18, 1876, repul. Jour. Iss. 
good doctor has really written the paragraph as it appears. He thinks there ought to be a register, of injuries which he thinks has happened, and he thinks if that mysterious record could be discovered it would "clearly prove that restraint does not diminish or prevent the occurrence of injuries from violence." Like the classic Arachne, here is a web of argument spun from internal consciousness; the unknown declared to be the known, and accurately conditioned to "clearly prove;" an assumption violent enough to form a casualty of itself, and held up in terrorem as proof. $A$. has a rabid dog that has been without sufficient control, and has destroyed many victims that are before us. $B$. has also such a dog, and therefore it must have been equally destructive, although $B$. has taken care to place said dog under restraint, and the supposed victims are not to be found. But apparently forgettul of his express regret that he had not asked for the register of accidents in his paper of March, the same distinguished gentleman, in an address before the Medico-Psychological Association on the 28th day of July, 1876, says: *

The Lancet censures me severely because I did not ask to be permitted to inspect the register of injuries and accidents. I should like to know if anybody has done so. If he has, I should like to hear him say so. I venture to think, that as a stranger in a far country, it was right not to return impertinence for courtesy, and that to do so is not the right way to obtain or impart information under such circumstances.

May it not be that there was a morbid expectation of dark mysteries to be found amongst us? The same distinguished gentleman comments upon "the pallid and emaciated appearance" of certain patients he observed in this country, with the idea that they were poorly nourished, as follows : $\uparrow$

* Dr. Bucknill's speech before Medico-Psychological Association,;quoted Jour. INs., Jan., 1875.

†Dr. Bucknill, JouR. INs., Oct. 1876, pp. 141-2. 
I know nothing of their dietary which, indeed, I have found to be a rather mysterious subject in all American asylums. I do not know that $I$ ever met with a printed dietary in any American asylum or asylum report.

I leave to my brethren the task of reply to this criticism, merely observing that while it may be quite true that we do not print so much about what our patients are fed upon, when one reflects upon the com. parative cheapness of the food in the two countries, especially in the article of meats, as universally used in this country, and by good authority, declared to be with difficulty sparingly obtained by the agricultural popu. lation of England, and more sparingly in Ireland, we think it is not necessary to expend much time and labor in reply. We do not feed our patients with Australian canned meat, it is true, but fancy that beef, with its juices, fresh from the meadow is no mean substitute. One thing we confess; beer is not an article of daily diet, but stimulants are with us, strictly employed as medicines.

We are puzzled to understand, upon the theory of slow starvation of our patients, how it comes to pass, that with fewer attendants and cheaper markets for provisions, the per capita expense in this country is so large, and in many cases, far beyond the per capita expended in England

But this topic is a digression from the consideration of restraint, and has only been alluded to by reason of the alleged mysteries in American asylums. Have my brethren any objection to relating the history of their several institutions, in relation to injuries and accidents? We trow not. Under no system may we hope to escape them altogether, so long as the insane man is what disease has made him. 
In a paper entitled " $A$ Report on the Management of the Insane in Great Britain,"* prepared with the sanction of the authorities of the State of New York, and published under the authority of the Board of Charities of that State, by H. B. Wilbur, M. D., of the Idiot Asylum, Syracuse, N. Y., appears the following.

In looking through the reports for 1874 , of twenty British asylums, containing in the aggregate about 15,000 patients, I find that iere were but seven accidental deaths, these nearly all paralytics or epileptics; and only five suicides.

He does not see the one hundred and sixty instances of acciclents within the asylums of Scotland for the same year, as given in the Annual Report of the Com. missioners, but straightway compares the returns of his twenty selected English asylums with the reports of thirteen institutions in the State of New York, with twelve suicides, in 3,500) population.

The distinguished gentlemen who represent here the great Empire State, may speak for their own enlight. ened Commonwealth, as no others can. But I will say, in no spirit of boasting, but in that of reverent gratitude to Almighty God, that in North Carolina, in the Asylum at Raleigh, over 1,200 patients have been treated, through a period of over twenty one years, and yet not a single suicide or homicide stands on its records. In fact, there is no list for the inspection of the visitor, whether he ask it or not, because, under Providence, it has not begun.

Long immunity has not, howerer, induced us to throw away mechanical restraint in certain cases, but has the rather confirmed us in its use. I doubt not that many asylums in America can show a similar his. tory. Results, after all, must settle a question like this.

* Report on the Management of the Insane, in Great Britain, Dr. Wilbur, pub. by Board of Charities. Note, p. 40. VoL. XXXVI -No. I-D. 
In considering the practical status of the question of the use of restraint among the Superintendents of Asylums in the United States, page upon page might be cited to show the firm and unwavering, but liberal and moderate conservatism of their views.

Some recent expressions of sentiment are as follows. In the Report of the Butler Hospital, Providence, R. I. appears:*

In another quarter, it is claimed that everything depends on the remoral of mechanical restraint, and leaving every patient to his own responsibility in taking care of himself. In the matter of mechanical restraint, it has always been the aim of our Superintendent to employ as little of it as was consistent with a proper regard for the safety of the patients, and the tendency has constantly been in the direction of an increasing freedom, although restraint is by no means abolished.

Dr. Catlett of the Missouri State Lunatic Asylum, No. 2, at St. Joseph, after recounting forms of restraint in use, says: $\dagger$

It is far better than the personal efforts of one or more attendants, even if it were possible to command their services both during the day and night.

The authorities of the Vermont Asylum say in a recent paper: $\ddagger$

To the complaints that the Institution has locked doors and mechanical restraints, we have only to reply that we have in use no safeguards or restraints not deemed essential to the proper management of every similar institution throughout our land.

Nowhere, however, do we find more happy expression on this point than in the Report of Dr. Curwen, for $1876 . \S$

\footnotetext{
* Report, Butler Hosp., Providence, R. I. 1877.

† Report Missouri State Lunatic Asylum, No. 2, St. Joseph.

‡ Trustees Vermont Asylum, 1876, p. 15.

§ Pennsylvania Insane Asylum at Harrisburg, pp. 18, 19.
} 
Experience and knowledge of the habits and feelings of those with whom they are daily brought into contact, have led the physicians of the hospitals for the insane in this country to prefer the use of such forms of mechanical restraint to the manual force of four or six persons; for in this latter case there is always sure to be a struggle, and neither the patience of Job, nor the meekness of Moses, nor the love of John, are inherent qualities in those who must perform such offices, nor, it must be frankly stated, if a judgment can be formed from the tone of their writings, in those who so urgently demand the abolition of all mechanical restraint.

It is not reasonable to believe, and as a proof of the statement let any one try it in his own person, that an excited, restless person suffering from acute maniacal excitement, will be as likely to sleep calmly and refreshingly with one person holding each arm, and one holding each leg, and a fifth holding the head, when the disposition so common when that number of persons are together to express freely their opinions on various subjects, as when the same patient is laid on a bed, and so fastened as to be able to turn from side to side, but not to rise from the horizontal position, a sleeping potion administered and every thing removed which can attract attention, or cause noise and confusion.

Besides, anyone who has witnessed the trial of the two methods must admit that the latter is infinitely preferable on every account, not only as far less likely to cause bruises, sprains or injuries to the patient, but also as much less irritating to the feelings and passions, and the canse of fewer angry words.

'There are, however, some differences of opinion regarding treatment expressed. Here and there the strictures of our critics would seem to have impressed some of our brethren, and an eager disposition is manifested in some quarters to disavow the use of restraint. It is this fact which excuses the presentation of a paper upon a subject which has in former years, received such careful consideration.

'Thus, we read in the Annual Report for 1876, of a far western hospital for the insane, ${ }^{*}$ the following:

* Report of the Trustees of Nebraska Hospital for the Insane, 1876. Dr. F. G. Fuller. 
There is, however, one feature of the management to which we wish to call especial attention; it is the almost entire absence of mechanical restraints upon the patients.

Page 56 of the same document, under Rejort of Matron has this entry-" 6 Camisoles!"

In another report for 1876 , proceeding from a member of this Association, whose valued services in the cause of humanity we all recognize :*

I said that the system of absolute non-restraint was confined to a few of the best British Institutions. We are pretty confident that there are none in this country in which its strict observance has been found, either expedient or practicable. In many other respects the American hospitals are superior to those of every other country, but it must be confessed, if the facts we have stated above be correct, that we have much to learn of the management of the insane from our friends across the water.

After relating lisciplinary measures to insure vigilance on the part of attendants, by which means he has obtained the best, he continues:

We claim that the practice of manual restraint has almost ceased to exist in this hospital. There has never been one cent expended in leather muffs for the hands, bedstraps, restraining chairs, or any of the elaborate apparatus of the kind which is manufactured expressly for the use of hospitals for the insane. . . . It is occasionally found necessary to place an excited patient in his room for a few hours, and in extreme cases to confine his hands to prevent destruction of clothing or self-injury, while the nurse is otherwise engaged; but these are exceptional cases, and under a more liberal management than our present limited income allows, might never occur. The kind remonstrances, often the mere presence, of a faithful patient nurse, will soothe, in the large majority of cases, the maniacal excitement which restraint too often intensifies. We mention these things because they are truths which go to confirm the English view of the practicability of non-restraint in the institutions of this as well as other countries, and may encourage others, as they do us, in the hope and effort to abolish

* Alabama Insane Hospital, 1876, p. 25. Dr. Bryce. 
completely and forever, the last vestige of that ancient abuse which the immortal physician of the Bicêtre was the first to demolish.

It is stated in the above report with regret that during the past year two suicides occurred, one by hang. ing, the other by drowning; being the first in the period of fifteen years. The case of drowning occurred in a patient who left the model attendant referred to, and plunge $l$ in to the river near by. Alas, that the parallel to the English system of non-restraint should be so sadly suggested. We ask with all respect and honesty of purpose, if it be in taste, to create an erroneous puslic sentiment among the masses of the people, by stigmatizing as "the last vestige of an ancient abuse," that which the voice of the profession has pronounced a means of medical treatment.

Why not arraign a Brown-Séquard or a Nélaton when they administer the actual cautery, as clinging also to the last vestige of the torture chamber?

In view of the repeated and sometimes malignant assaults upon American asylums, within the past year or two it may be as well to state that we have no argument whatever with such journals as the London Lancet. A writer is worthy of scant esteem who is capable of such a sentence in reference to American Medical Superintendents as "their practice has no claim to be classed as medical, hardly can it be called humane," who says that they (we) are "low and brutal," and who states as a fact that "they use, at least, the hideous torture of the shower-bath, as a pun. ishment, in their asylums, although it has heen eliminated from the discipline of their gaols." Indeed, the word that most fitly describes such a so-called fact, is a brief one that would disfigure these parges to give it expression. This writer, as on would suppose from 
Journal of Insanity. [July,

the gross ignorance he shows, is without knowledge of us or of his subject, who, however, makes up in conceit what he otherwise lacks.

Nor is it perhaps necessary to review the recent declarations of Dr. H. B. Wilbur, in a paper entitled "Governmental Supervision of the Insane,"* read before the American Social Science Association, and intended to show how far behind our English brethren, this close corporation of American Superintendents is and how it has been left in darkness, waiting his illuminated re. search. It is perhaps sufficient to quote the concise judgment of the editor of the Journal of Insanity, as follows:

The only comment we have to make is, that if Dr. Wilbur had practical familiarity with the subject of insanity, and any adequate personal knowledge of such institutions in bis own country, he might not have seen such wonderful things abroad.

Or for the benefit of those friends to whom distance lends enchantment, we might recite the views of a learned writer in the British and Foreigu Medico.Chi. rurgical Review, (July, 1876,) concerning Dr. Wilbur's report on the English asylums.

The Doctor's facts are of course, inexpugnable, but his impressions are derived from a few selected, celebrated establishments, and are contemplated through an atmospheve so couleur de rose, that an Englishman standing by his side, but tmbracing the whole field of vision, would scarcely recognize the picture, and might be inclined to look forward to such havens of rest as a premium on folly, and a solatium for all the ills that life is heir to.

Article VIII of the Oc $\_$ober number 1876 , of the Journal of Psychological Medicine and Mental Pathol. ogy, upon Mechanical Restraint in the Treatment of the Insane, written by F. Murchuson, M. A., M. B.; Edinburgh, assistant physician, Crichton Royal Insti- 
tution, Dumfries, does not hesitate to proclaim the truth thus:

The extreme opinions at one time prevalent in Britain, adverse to restraint, have never obtained the same countenance or favor in France, America, \&c., where mechanical contrivances still form a part of treatment. Even in this country the conflict between the dictates of professional duty and humanitarian sentimentalism is less keen than it was some years ago. The bugbear dread of public criticism has farled in cases where life or limb is known to be in danger.

"It is my firm conviction," says the writer again, "that the absence of mechanical restraint is the cause of the great majority of accidents, and of many of the suicides that take place in asylums ; and that at the present day a diminution of the freedom of the patient, by restraint or seclusion, would minimise and perhaps abolish, these undesirable items in the statistics of asylums."

He gives numerous cases of the essential service of restraint, and advocates earnestly a disregard of popular clamor in the performance of duty.

It will be remembered by those who were present at the Nashville meeting in 1874, that Vice President Walker, then presiding, at the close of the disçussion on this topic, made the following important declaration, from his own personal experience.*

I was gratified when visiting the institutions in England, the few I did visit, to find that almost universally,-certainly in fourfifths of the cases, the superintendents expressed themselves in favor of mechanical restraint, and singularly enough, the superintendents lay the blame of non-restraint upon the commissioners in lunacy, and the commissioners in lunacy throw it back upon the superintendents. They say the superintendents are emulous, one of another, to report the smallest number of restraints during the year. Certainly in my presence, and that of an American medical friend accompanying $m 2$, almost without exception, they expressed their preference for mechanical restrain:, and hoped they would have it established there. From an ex yerience of over twenty years, and from a careful, and I hope by no means super-

*JodRnal OF Insanity, October, 1874, p. 182. 
ficial study of this question, I firmly believe, that in the future, the practice of our best American asylums now, will become the governing rule of Christendom.

This is the deliberate, well considered statement of one of the oldest officers, and one of the thirteen founders of this association, made of his own knowledge.

Dr. Bucknill recites these assertions of Dr. Walker at length, and says in reply:

I must resist the strong temptation to treat the above in the manner it invites, yet how to treat it seriously I scarcely know. Yet it is a most serious matter, and reveals the true foundation of the American prejudice-namely, profound ignorance of what has really been done, and is yet doing in this country.

Ignorant! Yes-but we thought we had a Kirkbride among us, whose fame might even follow a Bucknill around the world. Prejudice! Yes-but we thought we had a Gray whose cool and impartial Journal of INSANITY has no superior anywhere! We thought we had a score of men competent to know what might be at the end of a week's journey!

We fear much is to be forgiven to the pugnacious nature of the distinguished gentleman. When Dr. Peddie refuses longer to discuss a grave question with him, in the Journal of Mental Science, because of the violence of his expressions, we must excuse the infirm. ity of speech which says of Dr. Walker's remark regarding the peculiarity of the American mental temperament, in connection with the need of restraint.

Verily we believe that this spread-eagle apology for the bonds of freemen is the most feeble, futile and fallacious which could possibly be imagined.

Or again, as he says of Dr. Hughes, that his remarks "are not worthy of an answer," and in the same breath accuses Dr. Ranney of "highfaluting" and "insincerity 
that he must have felt." Faith, we are tempted to rub our eyes, and look about us for a Donnybrook Fair!

To others we must leave his harsh criticisms upon the "cooked air" in which our patients live, their mysterious dietary, their want of exercise, and non-participation in labor, their costly homes, and more than all, the dreadful deprivation of the great right arm of a Commissioner in Lunacy whereby "they lag lamentably behind the science of their age."

Leaving these topics to be discussed by other pens, we will say before parting, that the distinguished gentleman has paid some just tributes to some noble men on this side the Atlantic, who inspired him with personal regard, and that especially for his manly defense of President Nichols, before the Medico-Psychological Association, he deserves, and will receive the thanks of American Superintendents.

His challenge has been answered. "Frank" enough is our reply, and we also trust, as "fair."

According to Dr. Wilkins' carefully calculated report, the average percentage of mortality in American Institutions may be estimated at seven per cent. In the Institution at Raleigh, for the last ten years, it has not exceeded an average of over four per cent. annually.

There are two questions we would ask, with all due respect.

How comes it to pass that the last report of the English Commissioners announces a death-rate of $\mathbf{1 1 . 3 6}$ per cent. for the year upon the average daily number resident? So says the Journal of Mental Science for January, 1877. What, nearly one-eigith in one year? Can this be true? I will not imitate your example, Dr. Bucknill, and say that the want of mechanical restraint is the great stumbling-block, nor will this humble pen dare to impugn my good brethren in England. But 
from the hollow depths of this abyss of mortality, a voice cries that something is wrong. Where is the Lancet Commissioner.

Our severe critic, and in some regards justly so, has pictured in thrilling language the condition of Blackwell's Island and Blockley Almshouse;-evils that our people are striving to remedy; as soon as it may be practically performed, and all he says of the wrong of partisan political interference is wise. But let Dr. Bucknill read of the local Irish asylums at his door, in the same journal,* and note this paragraph :

We think that where Governors refuse to provide beds and bedsteads for their increasing numbers, and keep patients lying during a hard winter on straw placed on the floor, as we have known them to do, the inspectors ought to possess a definite power of interference.

May we not commend that Eastern saying to our friend which has been happily translated. "Know most of the rooms of thy own country before thou crossest the threshold of another."

For ourselves, my brethren, we stand or fall, not upon the opinions of others, but upon the performance of a sacred duty; not in blind adherence to any theory, but such as experience may recommend. Let us see above all things, that we use and do not abuse, any means of treatment God has placed in our hands for the protection of his stricken creatures, and we may tear not when they and we come to a final judgment before the Eye that seeth all hearts.

As for our critics, let us rather thank them. The wise Abbe de Raunil said : $†$

Did a person but know the value of an enemy, he would purchase him with pure gold.

* Journal Mental Science, January, 1877, p. 597.

† Quoted in Basil Montague. 